\title{
Erring on the side of phonology
}

\author{
Patrycja Strycharczuk ${ }^{1}$ and Koen Sebregts ${ }^{2}$ \\ ${ }^{1}$ Queen Margaret University / ${ }^{2}$ Utrecht University
}

\begin{abstract}
Speakers of Standard Dutch increasingly realise coda /r/ (e.g. paar) as a bunched or retroflex approximant. This coda variant is categorically distinct from onset /r/ (e.g. reizen), which is typically pronounced as a uvular trill or fricative, or an alveolar trill or tap. In this study, we investigate whether coda and onset $/ r /$ in Dutch behave as distinct phonological categories. We present new articulatory and acoustic data on the realisation of $/ \mathrm{r} /$ in sandhi contexts, including the fake geminate context (e.g. paar reizen). Ultrasound data show that the presence of an onset $/ \mathrm{r} /$ conditions the deletion of a bunching gesture (typical of the coda $/ \mathrm{r} / \mathrm{re}$ alisation) from $/ \mathrm{r} \# \mathrm{r} /$ sequences. Nevertheless, the presence of a coda $/ \mathrm{r} /$ in such sequences is still acoustically traceable. We interpret these findings as a result of shared phonological identity between onset and coda $/ \mathrm{r} /$, and discuss them in the context of the place of allophony within models of grammar.
\end{abstract}

Keywords: Rhotics, Standard Dutch, categorical allophony, contrast, sandhi, fake geminate, ultrasound

\section{Introduction}

Within the generative approach to the study of language, it is widely assumed that the grammatical architecture consists of a number of levels that feed into one other, but which are nonetheless separate. The modular concept of grammar entails a distinction between phonology and phonetics. In practice, however, defining this distinction is fraught with empirical and conceptual difficulties, as discussed by Ohala (1990), Pierrehumbert, Beckman \& Ladd (2000) and Scobbie (2007), inter alia. A recurring argument in these papers is that certain speech phenomena occupy an intermediate 'grey area' between phonology and phonetics, evading a straightforward categorisation. This is often the case with allophonic variation. From a structural point of view, the realisation of allophones is predictable, and so allophones are not distinguished at the level of underlying representation. Furthermore, some authors have proposed that the criterion of predictability can 
also be used to define the scope of phonological computation. This proposal has been perhaps most explicitly elaborated by the Toronto School (Hall 2007; Avery, Dresher \& Rice 2008; Dresher 2009), who argue that the phonological component is concerned with distinctive features defined top-down, based on contrast and phonological behaviour. A similar view of the role of phonology follows from the assumptions underlying Enhancement Theory (Stevens, Keyser \& Kawasaki 1986; Stevens \& Keyser 1989; Keyser \& Stevens 2006; Stevens \& Keyser 2010). According to Stevens \& Keyser (2010), underlying representations contain only distinctive (i.e. contrastive) features, and mapping between underlying and surface representations does not operate on features.

A stringent contrast-based approach would reject the phonological status of allophonic variation, unless such variation is generated by changes to contrastive features. However, many cases of non-contrastive allophony have been analysed as phonological, for instance American English /t/-flapping (Kahn 1980; Nespor \& Vogel 1986). On the other hand, the rounding of $/ \mathrm{k} /$ before back vowels never features in phonological analyses. The criteria for treating some processes as phonological allophony are not always clear-cut, which has led some linguists to question the rationale behind positing the level of allophonic representation (e.g. Browman \& Goldstein 1992). However, a growing body of empirical research shows that gradient and categorical processes can be distinguished below the level of the phoneme, which supports the phonological status of some cases of allophony. For instance, the previously mentioned case of / $/$ /-flapping has been shown by Herd, Jongman \& Sereno (2010) to involve distinct phonetic categories. Similarly, an empirical case for categorical allophony has been made for the word-final glottalisation of English voiceless stops (Kingston \& Cohen 1992), for /1/-darkening in English (Yuan \& Liberman 2009; Turton 2013), for positional variation of nasals in velarising Spanish dialects (Ramsammy 2013) and for the voicing realisation of /s/ in Quito Spanish (Strycharczuk, van't Veer, Bruil \& Linke 2013).

The accumulating laboratory evidence seems to support positing a level of categorical allophony, but it is not yet clear whether subphonemic categories are in any sense salient to language users, or whether they show distinct empirical behaviour compared to contrastive categories and compared to lower-level variation. We probe some of these questions in the current study, by focusing on the phonological and phonetic behaviour in Dutch /r/-allophony.

Previous research by van de Velde (1996), Sebregts, Tops, van Bezooijen, van de Velde, van Hout, Willemyns \& Zonneveld (2003) and by Scobbie \& Sebregts (2010) shows that $/ \mathrm{r} /$ in Dutch is subject to considerable variation, in which the following broad generalisations can be discerned. In codas, $/ \mathrm{r} /$ is realised as a postalveolar approximant, which may be articulated either as retroflexed (with tongue tip up or curled back), or as bunched (with tongue tip down). The onset variants 
clearly contrast with the coda ones in place of articulation, as we typically find either uvular or alveolar consonants in onsets. Within those two groups there is further variation in manner. The uvular variants may vary from trills, through fricatives to approximants, whereas the alveolar variants are typically taps or trills. The variation is conditioned by dialect, but inter-speaker differences within dialects are also found. The distribution of / $\mathrm{r}$-variants within speaker is structurally predictable, though gradient within larger prosodic categories, and there are no lexical contrasts involved. At the same time, the results of the study by Scobbie \& Sebregts (2010) show that some speakers of Dutch realise /r/ as two categorically distinct allophones. Therefore, while coda and onset $/ \mathrm{r} / \mathrm{might}$ form a single category from the point of view of lexical contrast, phonetic evidence suggests that they might be two categories on the phonological level. Building upon this, we investigate how the allophones of $/ \mathrm{r} /$ interact with each other in connected speech, compared to how they interact with contrastive categories. We analyse the articulatory and acoustic realisation of $/ \mathrm{r} /$ in a variety of contexts, including canonical coda and onset positions ( $\mathrm{r} \# \mathrm{C}$ and $\mathrm{V} \# \mathrm{r}$ respectively), as well as the fake geminate context $(\mathrm{r} \# \mathrm{r})$. The comparison was guided by the following research questions:

1. Do we see evidence for a categorical coda-onset distinction in acoustics and articulation?

2. How is the allophony realised when coda and onset $/ \mathrm{r} /$ are immediately adjacent?

\section{Materials and method}

For our study, we collected production data from four native speakers of Dutch. The speakers were screened prior to the experiment on their use of a post-alveolar approximant coda variant. Three of the speakers were female (SU1, SA1 and SA2), aged 20-24. One speaker (SU2) was male, aged 20. SA1 and SU2 were from Gouda, SU1 was from Amsterdam and SA2 was from Ede. Impressionistically, all the speakers spoke Standard Dutch, as evaluated by the second author.

The speakers read test items which included / $\mathrm{r} /$ in five systematically varied contexts: word-initial intervocalic $(\mathrm{V \# r})$, word-medial intervocalic $(\mathrm{VrV})$, word-final pre-consonantal $(\mathrm{r} \# \mathrm{C})$, word-final prevocalic $(\mathrm{r} \# \mathrm{~V})$ and the fake geminate context ( $\mathrm{r} \# \mathrm{r}$ ). The segmental context and word stress were controlled for (cf. Table 1 and Appendix A). The test items were embedded in lexically meaningful sentences. All these sentences were questions, so as to keep the intonation patterns comparable. In addition to the 10 test sentences, 14 distractor sentences were included in each block to prevent the participants from guessing the purpose of the study. 
Table 1. Test items used in the study

\begin{tabular}{llll}
\hline Word-initial onset & $\mathrm{V} \# \mathrm{r}$ & pa reizen & pa raden \\
Word-medial onset & $\mathrm{VrV}$ & Parijzenaar & parade \\
Canonical coda & $\mathrm{r} \# \mathrm{C}$ & paar meisjes & paar baden \\
Word-final prevocalic & $\mathrm{r} \# \mathrm{~V}$ & paar eisen & paar ademen \\
Fake geminate & $\mathrm{r} \# \mathrm{r}$ & paar reizen & paar raden \\
\hline
\end{tabular}

(1) Example prompt sentence:

Heb je een paar reizen naar Manchester gemaakt?

'Have you made a few trips to Manchester?'

The recordings took place at the University of Manchester Phonetics Laboratory. Articulatory and acoustic data were collected simultaneously. The articulatory data were collected using a Mindray DP2200 ultrasound machine at the rate of approximately 30 frames per second. A probe was placed under the participant's chin and stabilised using a helmet (Articulate Instruments Ltd., 2008). The acoustic data were collected using a lavalier Audio-Technica ATR3350 condenser microphone connected to a PC. The microphone was clipped to the helmet worn by the speaker, about $10 \mathrm{~cm}$ from the speaker's mouth. The audio data were sampled at $22050 \mathrm{~Hz}$.

Three repetitions of the test items were recorded per speaker in three blocks. The items were semi-randomised within each block, avoiding immediate repetitions. The prompts were presented to the speaker on a computer screen, using the Articulate Assistant Advanced software (AAA, Articulate Instruments Ltd., 2010). One prompt was presented at a time. The speakers were instructed to read at a natural pace. 120 test items were recorded altogether $\left(10\right.$ items $* 4$ speakers ${ }^{*} 3$ repetitions). One item had to be discarded, due to a recording error.

The acoustic analysis was carried out in Praat (Boersma \& Weenink 2009). We analysed the spectrograms visually on a $5 \mathrm{~ms}$ Gaussian window, and inserted boundaries indicating the onset and offset of $/ \mathrm{r} /$, as well as the onset and offset of the preceding and the following segment. In the case of the uvular fricative and alveolar tap/trill, the rhotic was identified based on a drop in amplitude. The segmentation is exemplified in Figure 1. In the case of postvocalic approximant $/ \mathrm{r} /$, it was not possible to reliably mark the boundary between the rhotic and the preceding vowel (cf. Figure 2 ). In such cases, we measured the duration of the entire vowel $+/ \mathrm{r} /$ sequence. We also measured F2 and F3 at $10 \%$ intervals in the vowel $+/ \mathrm{r} /$ sequence, using the Burg algorithm in Praat. The formant settings were adjusted for each speaker to ensure accurate formant tracking. All formant measurements were further checked and manually corrected if tracking errors occurred. 

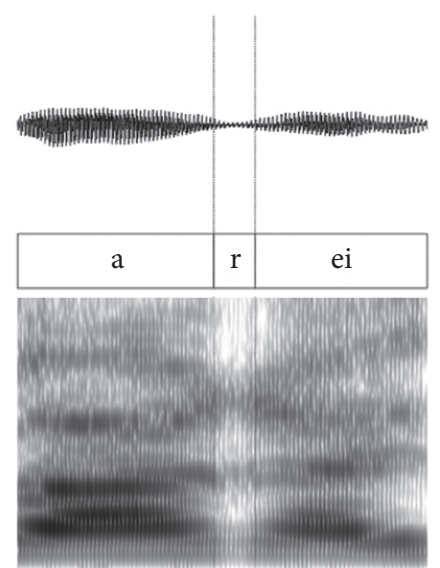
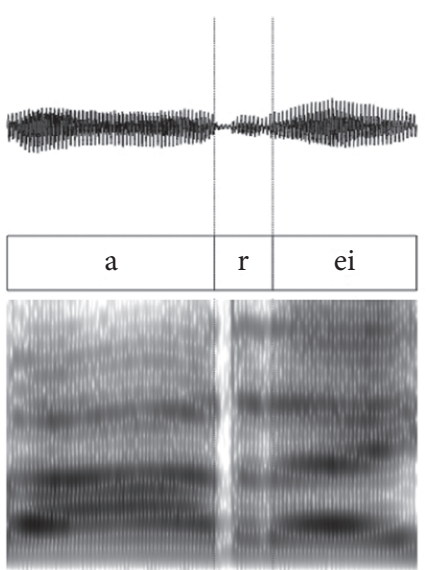

Figure 1. Oscillogram and spectrogram representing example segmentation of intervocalic uvular (left) and alveolar (right) intervocalic /r/

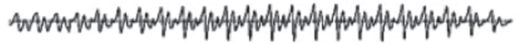

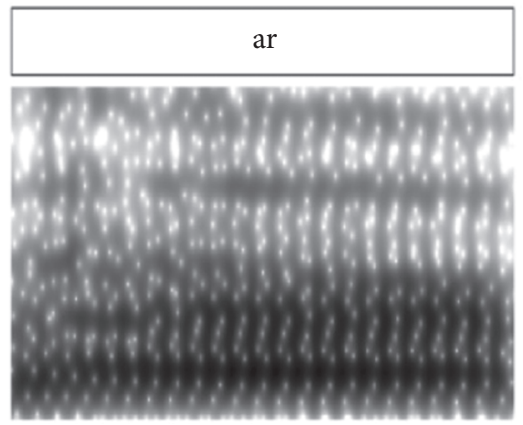

Figure 2. Oscillogram and spectrogram of a postvocalic approximant $/ \mathrm{r} /$ with no clear acoustic boundary between the vowel and the rhotic

The articulatory analysis was performed using AAA. The output of the ultrasound recording involves individual frame pictures taken at regular intervals (every 30 $\mathrm{ms}$ ) throughout the recording. Each frame depicts the shape of the tongue in a midsagittal plane, with the tongue tip on the right. For every test item, we identified one frame that was representative of the rhotic, using acoustic criteria. If we could observe a clear F3 drop during /r/ articulation in the acoustic signal, we selected the frame that was most closely aligned to that acoustic event. ${ }^{1}$

If no clear F3 drop could be observed, we chose the frame most closely aligned to the midpoint of the rhotic. Having selected the relevant frame, we manually fitted a line tracing the shape of the tongue, as illustrated in Figure 3. We henceforth 

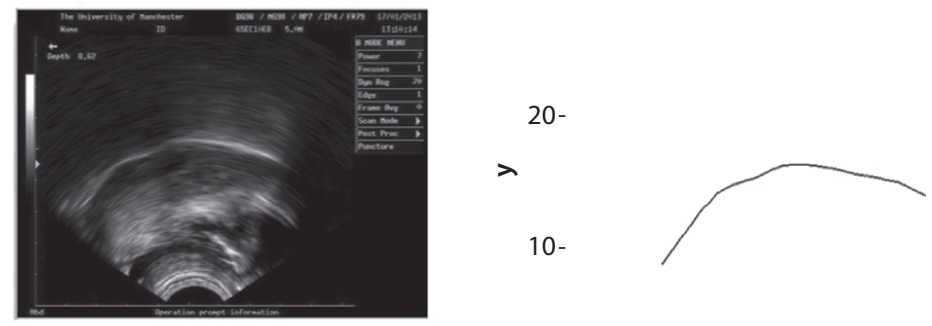

$0-$ $0^{1} \quad 10 \times 30$

Figure 3. Example of tongue surface tracking for an alveolar $/ r /$. The picture on the left shows an ultrasound frame representing the tongue shape during alveolar $/ \mathrm{r} /$ production (midsagittal plane, tongue tip on the right). The picture on the right shows a spline representing the tongue surface extracted from this image.

refer to these as 'splines'. All splines were drawn within a single reference frame for each speaker. Their coordinates (42 points per spline) were then exported for analysis in R (R Development Core Team, 2005).

\section{Results}

\subsection{Allophony patterns}

Based on visual inspection of spectrograms and the auditory impression of speakers' realisations, two types of allophony systems could be discerned among the participants. Speakers SU2 and SU1 had a uvular approximant in onsets and an anterior approximant in codas. Speakers SA2 and SA1 had an alveolar tap/trill in onsets and an anterior approximant in codas. This auditory generalisation was confirmed by patterns found in articulatory and acoustic data. Figure 4 illustrates the articulatory and acoustic realisation of onset and coda / $\mathrm{r} /$ (in the phrases $p a$ reizen and paar meisjes respectively) by speaker SU1. The ultrasound frame in the top panel shows a typical articulatory realisation of an onset $/ r /$ for this speaker with the tongue dorsum raised. Acoustically, this pronunciation was reflected in an intensity drop, compared to flanking vowels, as shown in the spectrogram in the lower panel. The spectrogram also shows a discernible formant structure and voicing present throughout the rhotic, which indicates that the sound is more accurately analysed as an approximant than a fricative. In comparison to onset $/ \mathrm{r} /$, the coda /r/ (in the right-hand panel of Figure 4) shows a few distinct characteristics. The sound was articulated as a bunched approximant, with pre-dorsum raised 

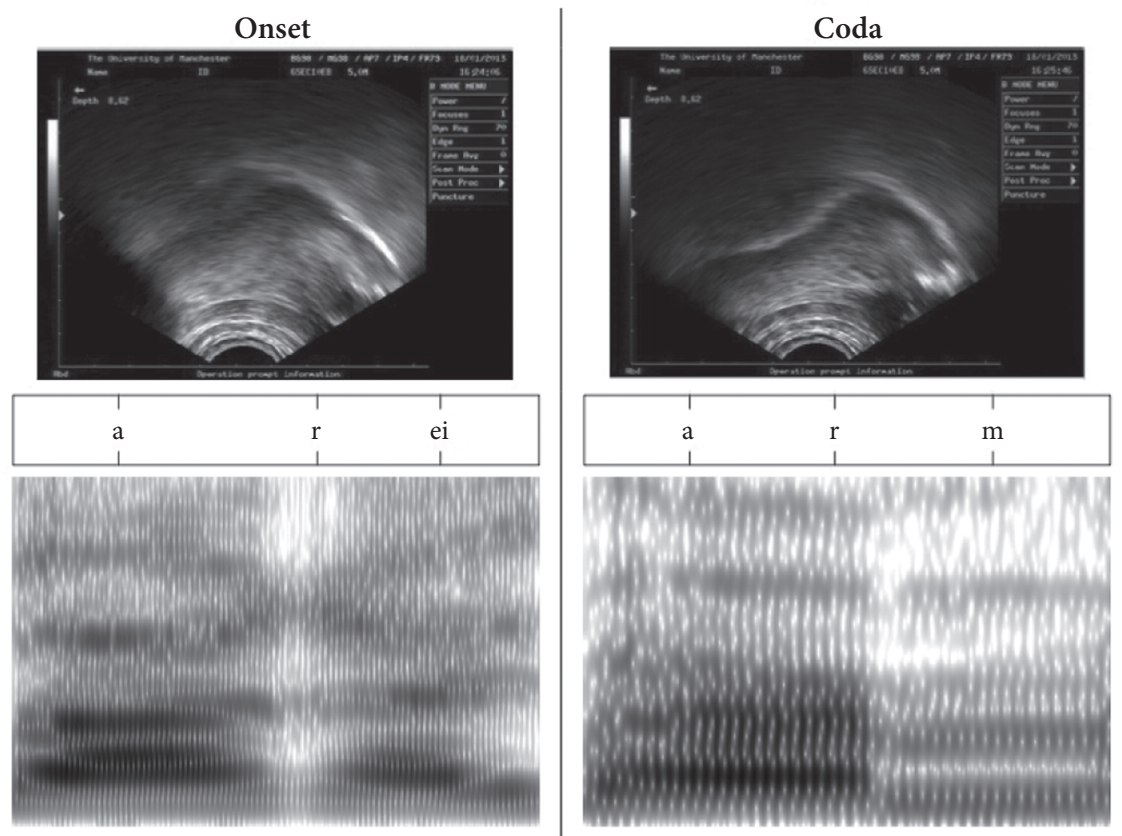

Figure 4. Articulatory and acoustic realisation of onset and coda /r/ by speaker SU1

and tongue tip down. Acoustically, this was reflected in a gradual drop in intensity coupled with a downward F3 slope.

Figure 5 illustrates the onset-coda allophony as realised by alveolar speaker SA1. The onset for this speaker was realised as an alveolar trill. The ultrasound frame in the top left-hand panel of Figure 5 shows the alveolar place of articulation, with the front of the tongue raised. Due to the low sampling rate of the ultrasound system, individual contacts could not be observed in the articulation. They can, however, be seen in the accompanying spectrogram, as evident from the series of low intensity portions, reflecting closures. This onset realisation was quite distinct from that of the coda $/ \mathrm{r} /$, as pronounced by SA1. As shown in the right-hand panel of Figure 5, SA1 pronounced coda /r/ as bunched, with tonguetip down and a characteristic saddle shape of the tongue. This was reflected in the acoustics as gradient decrease in intensity and F3 lowering.

All speakers were found to preserve the difference between coda and onset $/ \mathrm{r} /$ in articulation consistently. Figure 6 shows tongue positions for each speaker over the three repetitions and three vowel contexts. For uvular speakers SU1 and SU2, we see that the onset $/ \mathrm{r} /$ was pronounced with a posterior constriction and tongue dorsum raised. Coda $/ \mathrm{r} /$, on the other hand, was consistently realised with more anterior constriction and pre-dorsum raising. In the case of speaker SU1, this produced a very distinct saddle shape of the tongue. In the case of speaker SU2, the 


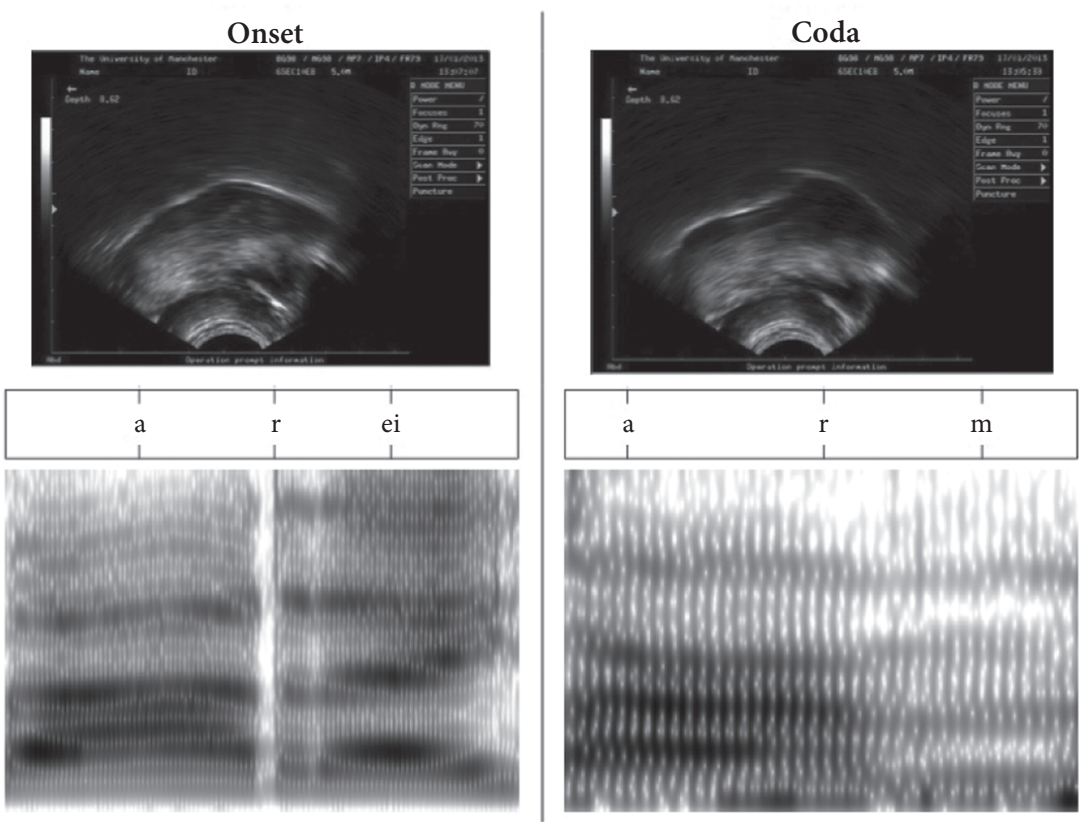

Figure 5. Articulatory and acoustic realisation of onset and coda /r/ by speaker SA1

saddle shape is less obvious, especially in the average spline, where it is partially obscured by smoothing, but the difference between the coda and onset allophones is nevertheless observable. Coda-onset allophony in articulation can also be seen in alveolar speakers, SA1 and SA2, as shown in the bottom panel of Figure 6. SA1 has clear bunching, i.e. raising of the pre-dorsum in coda and a raised tongue tip in

SU1

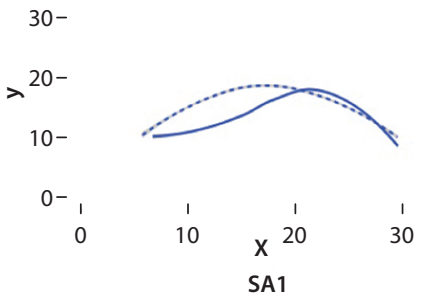

$30-$

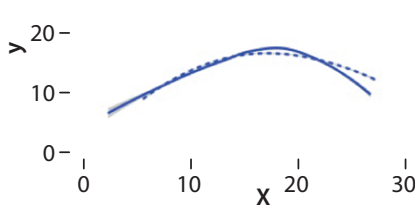

SU2

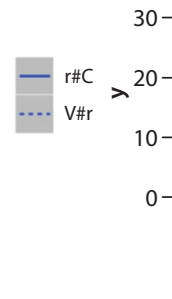

$30-$

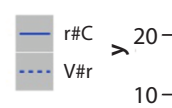

$0-\frac{1}{1}$

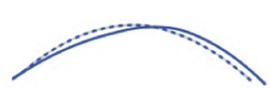

10

$x^{20}$

SA2

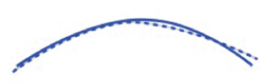

- r\#C
.... V\#r

Figure 6. Onset-coda allophony for all speakers 
onset. The bunching is much less obvious for SA2, although the tongue tip is down in coda, and it is up in onset.

\subsection{Fake geminate in articulation}

Let us now consider the realisation of the fake geminate context $/ \mathrm{r} \# \mathrm{r} /$ in comparison to canonical onset and coda. ${ }^{2}$ Figure 7 shows the same average tongue position in the coda and onset context by speaker, as previously seen in Figure 6, with the fake geminate context added for comparison. For three speakers, SU2, SA1 and SA2, there is almost complete overlap between the splines representing average tongue shape in the $/ \mathrm{r} \# \mathrm{r} /$ context and in the /V\#r/ context. For speaker SU1, there is a difference between the fake geminate context and the canonical onset environment, such that the former involves a relatively more fronted constriction. In terms of tongue shape, however, the fake geminate context is quite similar to the onset context, as both involve tongue dorsum raising. Unlike in the case of coda /r/ pronounced by speaker SU1, no bunching gesture can be observed in the fake geminate context.

\subsection{Acoustic results}

We analysed the acoustic measurements of /r/ duration, duration of the / $\mathrm{Vr} / \mathrm{se}$ quence and F3 in R, using mixed-effects linear regression. All models included random intercepts for speaker and item. In the models of duration, we considered how the duration was affected by context. For the / Vr/ sequence duration the

SU1

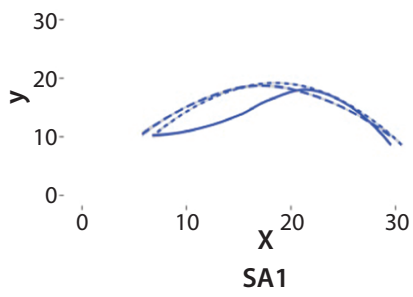

30

$\lambda^{20}$

10 -

0 -

0

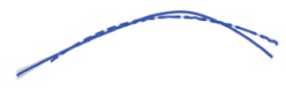

$10 \quad x^{20}$

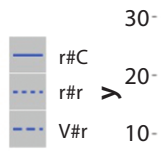

0.

0

$30-$

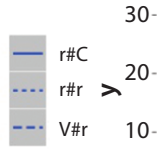

0.
SU2

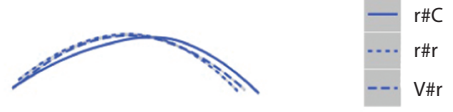

$10 \quad x^{20} \quad 30$

SA2

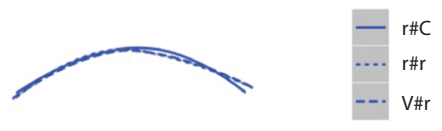

30

Figure 7. Fake geminate context in comparison to canonical onset and coda for all speakers 
context effect had three levels: onset / $\mathrm{V \# rV/,} \mathrm{coda} \mathrm{/} \mathrm{Vr} \# \mathrm{C} /$, or fake geminate /r\#r/. In the model of / $/$ / duration, we only compared onset $/ \mathrm{V} \# \mathrm{rV} /$ with fake geminate $/ \mathrm{r} \# \mathrm{r} /$, as coda / $\mathrm{r} /$ was not segmentable. Both models showed no significant difference in duration between onset and fake geminate context. The average difference between the two contexts for the VR sequence equalled $36.91 \mathrm{~ms}(p=.06)$, and the difference in $/ \mathrm{r} /$ duration was $2.75 \mathrm{~ms}(p=.76)$. The mean difference in VR sequence duration between the fake geminate context and the coda context equalled $74.08 \mathrm{~ms}$ and it was significant at $p=.001$. The duration differences are illustrated in Figure 8.

In modelling $\mathrm{F}$, we considered how the formant value (in $\mathrm{Hz}$ ) changed as a function of context (onset / $\mathrm{V} \# \mathrm{rV} /$, coda $/ \mathrm{Vr} \# \mathrm{C} /$, or fake geminate $/ \mathrm{r} \# \mathrm{r} /$ ) and time at which the measurement was taken (quantified as the percentage of the $/ \mathrm{Vr} /$ sequence). As an additional predictor, we included the following vowel ( $a$ vs. $e i$, which correspond to [ai] and [ei] respectively]), since formant values may be affected by long-distance coarticulation. We tested for interactions between the predictors through stepwise addition of the interactions to the model. After adding each interaction, we evaluated whether it improved the model fit according to the log-likelihood test (Baayen 2011). Based on this procedure, we found a significant three-way interaction between vowel, time point at which the measurement was taken and the following vowel. The interaction is plotted in Figure 9.

In general, $\mathrm{F} 3$ is lower in the coda context $(/ \mathrm{Vr} \# \mathrm{C} /)$, compared to onset $(/ \mathrm{V} \# \mathrm{rV} /)$. In addition, the F3 trajectory develops differently in the two baseline contexts. In onsets, F3 rises gradually throughout the / Vr/ sequence, whereas the coda context is characterised by steady F3 lowering. The fake geminate context
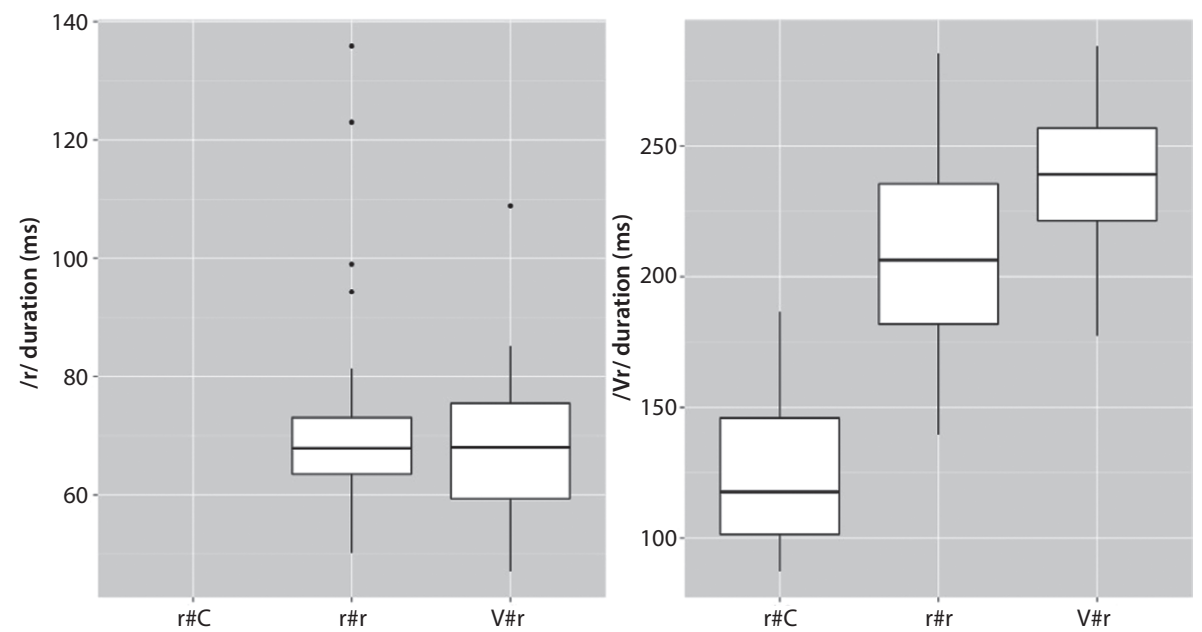

Figure 8. Left: /r/ duration (in ms) as a function of condition. Right: / $\mathrm{Vr} /$ duration (in $\mathrm{ms}$ ) as a function of condition. 


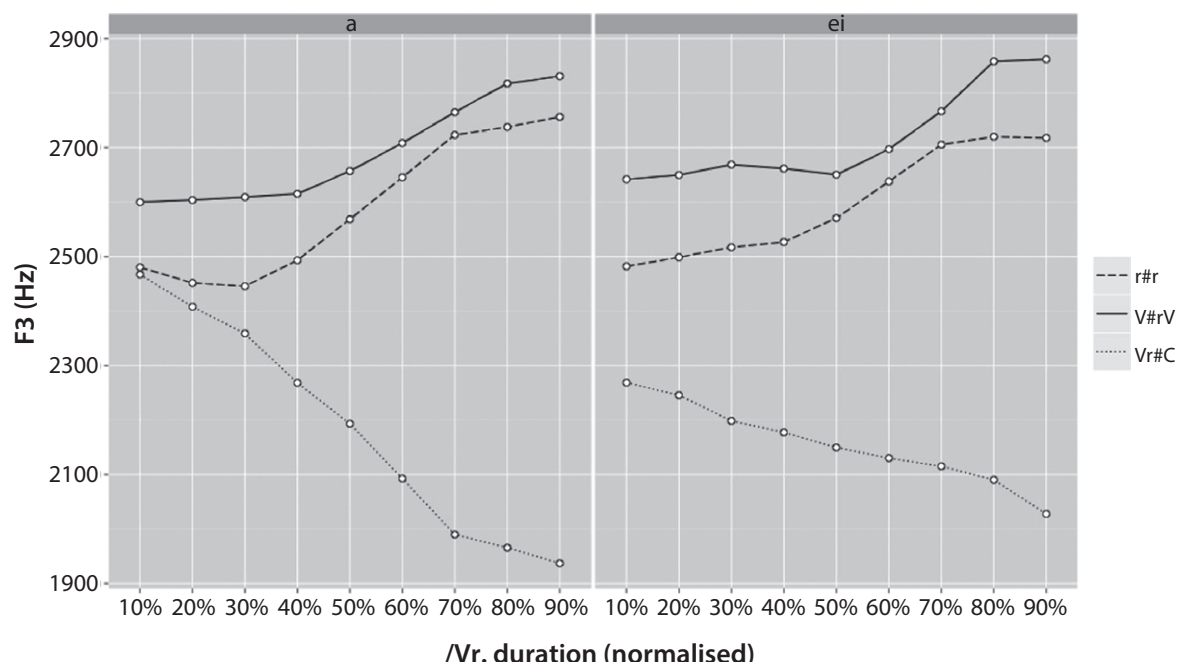

Figure 9. F3 (in $\mathrm{Hz}$ ) measured at $10 \%$ intervals through the $/ \mathrm{Vr} /$ sequence depending on the following vowel

does not pattern clearly with either onset or coda. In the initial part, some F3 lowering can be observed in the fake geminate context compared to onset. After that, however, F3 in the fake geminate context rises, patterning with the onset context. In order to test for the significance, we analysed the F3 values in comparison to onset and coda at all points of measurement. The summary of the results is in Table 2. In the initial part of the $/ \mathrm{Vr} /$ sequence (up to $30 \%$ into the sequence), the fake geminate context patterned with the coda context, but it differed significantly from the onset context. However, in the mid and in the latter part of the / $\mathrm{Vr} /$ sequence, the fake geminate context patterned with the onset, but it differed significantly from the coda.

Table 2. Summary of $\beta$ and $p$-values in a comparison of F3 value in the fake geminate context $(/ \mathrm{r} \# \mathrm{r} /)$ as opposed to onset and coda contexts. Significant differences are indicated by shading

\begin{tabular}{|c|c|c|c|c|c|c|c|c|c|c|}
\hline & \multicolumn{2}{|l|}{$10 \%$} & \multicolumn{2}{|l|}{$20 \%$} & \multicolumn{2}{|l|}{$30 \%$} & \multicolumn{2}{|l|}{$40 \%$} & \multicolumn{2}{|c|}{$50 \%$} \\
\hline & $\beta$ & $\mathrm{p}$ & $\beta$ & $\mathrm{p}$ & $\beta$ & p & $\beta$ & $\mathrm{p}$ & $\beta$ & $\mathrm{p}$ \\
\hline$\overline{\mathrm{V \# rV}}$ & 119 & .07 & 152 & .05 & 163 & .02 & 122 & .10 & 88 & .13 \\
\hline \multirow[t]{3}{*}{$\mathrm{Vr} \# \mathrm{C}$} & -13 & .80 & -28 & .60 & -87 & .17 & -225 & .008 & 376 & .001 \\
\hline & $60 \%$ & & $70 \%$ & & $80 \%$ & & $90 \%$ & & & \\
\hline & $\beta$ & $p$ & $\beta$ & $p$ & $\beta$ & $\mathrm{p}$ & $\beta$ & $p$ & & \\
\hline $\mathrm{V \# rV}$ & 63 & .43 & 42 & .64 & 80 & .48 & 74.73 & .44 & & \\
\hline $\mathrm{Vr} \# \mathrm{C}$ & -553 & .001 & -734 & .001 & -772 & .001 & -819 & .001 & & \\
\hline
\end{tabular}




\subsection{Summary}

The results obtained in this study confirm the existence of a categorical allophonic distinction in the realisation of $/ \mathrm{r} /$ in canonical onsets and codas. Our speakers differ as to how they realise the onset variant: Two speakers had a uvular onset variant, while the remaining two had an alveolar trill in the same position. For all the participants, however, the coda / $\mathrm{r}$ / could be roughly characterised as involving pre-dorsum raising and an anterior constriction. Acoustically, this was reflected in a relatively lower F3 value for the coda /r/. Onset and coda also differed with respect to the F3 trajectory: F3 was found to rise in onsets and fall in codas.

The fake geminate context was found to pattern with the onset context according to many parameters analysed in the study. The mean tongue shape for the two contexts (onset and fake geminate) overlapped almost completely for three out of four speakers in the study. A similar result was delivered by the acoustic duration measurements: Fake geminates patterned with onsets in terms of /r/ duration and $/ \mathrm{Vr} /$ duration, but both contexts differed significantly from codas. However, a difference between the coda context and the fake geminate context could be observed in the F3 value in the vocalic part of the / $\mathrm{Vr} /$ sequences, where the fake geminate context had a significantly lower F3 compared to the coda. A reviewer notes that the acoustic effect observed in F3 must be linked to some articulatory event, and asks whether the apparent absence of bunching in fake geminates may be a result of our analysing only one ultrasound frame per token. We have performed an analysis of the frames immediately preceding the ones we consider to be representative of the rhotic, but we found no evidence of systematic bunching. This might be due to the low sampling rate of the ultrasound system we used (30 frames per second). Indeed, it was not always clear that the frame preceding the target frame represented a part of the rhotic rather than the preceding vowel. More systematic analysis of the gestural dynamics of $/ \mathrm{r} \# \mathrm{r} /$ sequences would certainly be desirable, but it is not possible using the data we currently have available.

\section{Discussion}

Different sources of articulatory and acoustic evidence suggest that the bunching gesture typical of coda $/ \mathrm{r} /$ is extremely reduced, or perhaps deleted in the fake geminate context. Unlike in the coda context, no clear bunching gesture could be observed in the fake geminate context for any of the speakers in the study. The reduction interpretation is also supported by the acoustic results on duration, which show no difference in $/ \mathrm{r} /$ duration between the $/ \mathrm{r} \# \mathrm{r} /$ and the /V\#rV/ contexts: Fake geminates did not involve any appreciable / $\mathrm{r}$ / lengthening compared to singleton 
onsets. These generalisations are in contrast to the way /r/ behaved in the context of a following labial consonant, where the rhotic was consistently realised as bunched, with pre-dorsum tongue raising. All in all, we find that an onset /r/ variant exerts a very strong reductive influence on the preceding coda /r/. Importantly, the strength of the reduction in sequences is not easily explained from a phonetic perspective. While some motivation for the degree of reduction could potentially be sought in the relative phonetic similarity of neighbouring sounds, we would expect such an effect to be more gradient, also making a distinction in the effect triggered by uvular vs. alveolar $/ \mathrm{r} /$, which are phonetically quite distinct. Yet, we do not find a difference between different $/ \mathrm{r} /$ variants in conditioning reduction. This suggests that the extent of the reduction is due to phonological rather than phonetic factors. Surface / $\mathrm{r}$ / variants behave alike because they share an identity at an abstract phonological level, rather than due to phonetic similarities.

The common behaviour in exerting this reductive influence is predicted from the contrastivist point of view. If phonological categories are defined based on lexical contrast, different /r/ variants are expected to exhibit similar phonological behaviour, even if they are phonetically distinct. If phonological categories are taken to reflect phonetic categories, on the other hand, it is difficult to account for the similar behaviour with respect to reduction of phonetically distinct/r/allophones. At the same time, however, the data do not fully bear out the predictions which follow from the contrastivist viewpoint. While it could be argued that an onset $/ \mathrm{r} /$ triggers the deletion of a preceding bunching / $\mathrm{r} /$ gesture, the coda $/ \mathrm{r} /$ does not undergo full segmental deletion. Segmental deletion of a coda / $/ \mathrm{r}$ would entail complete phonetic neutralisation between the word-initial onset and fake geminate contexts (e.g. pa reizen would become homophonous with paar reizen). ${ }^{3}$ This, however, does not happen, as there is an F3 contrast between the two contexts. Specifically, F3 lowering could be observed in the initial (vocalic) part of the /Vr/ sequence in paar reizen type items. F3 lowering has previously been found to be an acoustic exponent of retroflex or bunched /r/ in English (Delattre \& Freeman 1968; Westbury, Hashi \& Lindstrom 1998) and Dutch (Plug \& Ogden 2003). Thus, we could hypothesise that even though the bunching gesture as such is reduced, its residue is still present in the acoustics. Note that this entails that there is at least another, parametric phonetic, level of representation. A similar F3 lowering effect has been observed in German by Lodge (2003), who notes that the presence of a coda rhotic may exert acoustic effects over a relatively large domain, affecting the preceding vowel even if $/ \mathrm{r} /$ itself is acoustically untraceable.

What emerges from our findings is that neither categorical phonetic behaviour nor contrast alone is sufficient to predict the full scope of the reduction effects present in the current data. While the contrastivist perspective correctly predicts that coda $/ \mathrm{r} /$ will undergo more reduction before an onset $/ \mathrm{r} /$ than before $/ \mathrm{m} /$ or 
$/ \mathrm{b} /$, it fails to explain why the coda $/ \mathrm{r} /$ is not subject to complete deletion. The presence of acoustic traces of coda / $/ \mathrm{r} /$ in the absence of an actual postvocalic approximant could be explained if distinct postvocalic/r/ features are present in the abstract phonological representation. Similarly, the presence of such features may result in intermediate articulations, such as those exhibited by speaker SU1. However, this entails that phonology can in fact see the difference between onset and coda / $/ \mathrm{r}$ / allophones. Thus, it would seem that both lexical contrast and phonetic characteristics contribute to shaping the content of the phonological component.

This observation is in line with Ladd's (2006) proposal that phonological categories can emerge from a number of different sources. Lexical contrast plays a major role in shaping categories, and so lexical distinctions are predicted to map onto phonological ones. However, phonetic distinctions which do not cue lexical contrasts may also be phonologically distinct as factors other than contrast also contribute to category formation. As examples of such factors, Ladd lists sociolinguistic distinctions, folk descriptions of sound types, language/dialect contact, and paralinguistic usage of potentially lexically contrastive sounds (e.g. different types of clicks used in English). As another factor, we would add categorical phonetic behaviour, as seen for instance in the Dutch onset-coda allophony, where the two variants involve categorically distinct articulations rather than gradient quantitative contextual adjustments. The perceived presence of categorical peaks in the continuous phonetic space may be taken by the language learner/user as indicating the presence of distinct phonological categories below the level of the phoneme.

Ladd (2006) argues that a multi-source view of category formation correctly predicts a range of empirical phenomena. For instance, acquisition studies have shown that babies may acquire phonetic categories at the pre-lexical stage. This can only be explained if such categories can exist independently of contrast. Another empirical observation which squares closely with the idea of multi-source category formation is the existence of morphosyntactic effects in allophonic variation, as discussed in Section 1.1 for the case of English /1/. Taking an analogical example of morphologically derived [ $\Lambda \mathrm{i}] \sim[\mathrm{ae}]$ contrast in Scottish English (e.g. in side vs. sighed), Ladd argues that contrasts like this constitute a case of what he terms 'partial similarity between phonemes.' The two categories are contrastive, forming minimal pairs such as sighed and side, although the contrast is structurally redundant. At some level however, [Ai] and [ae] are confusable to speakers of Scottish English. For instance, native speakers may be uncertain which allophone they use in disyllabic monomorphemic words, such as spider. Furthermore, the lexical distribution of the two allophones may vary from speaker to speaker. Ladd takes these observations as evidence that phonetic categories may be simultaneously similar and distinct at different levels of phonological representation. This can be 
represented by means of a hierarchical organisation of phonological categories. Such hierarchical organisation is intrinsic to many types of cognitive categories, such as for instance taxonomic distinctions within the animal kingdom. Ladd's example is from dog breeds: Collie and spaniel are distinct breeds, but at the same time they both belong to the category 'dog', and superordinate category 'mammal', as schematised in (2).

(2) Categories and subcategories generally (Ladd, 2006, p. 19)

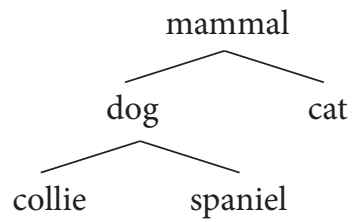

Extending the same proposal to the phonological domain, phonological categories could simultaneously be separate entities, yet belong to the same category at a higher level of representation. A relevant specification for the Dutch case is proposed in (3).

(3) Categories and subcategories in Dutch phonetic/r/ variants Phones

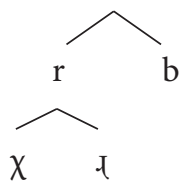

The hierarchical specification predicts that $\chi$ and $x$ are distinct phonological categories, which is consistent with the categorical distinctions in their phonetic production and perception. The phonological status of $\_$is also supported by the finding that coarticulatory influence of coda $/ \mathrm{r} /$ on the preceding vowel can be noted even when the approximant coda $x$ is not itself overtly realised. At the same time, $\chi$ and $\_$are non-distinct at a level of representation defined by lexical contrast. Hence, they are predicted to display more similarity than sounds which contrast along both phonetic and lexical dimensions.

The data presented in this work only provide evidence for a model with two levels of representations, one of which is defined by contrast and the other by phonetic characteristics and coarticulatory behaviour. In that sense, the representation is fairly close to the traditional phoneme-allophone distinction. The main significance of our findings is in providing empirical evidence for assuming a level of subphonemic phonological representation and in reiterating the need for specifying objective empirical criteria by which allophones can be defined. Importantly, in a model where phonological categories may be formed based on many sources 
of evidence and where such categories display partial similarity, more than two levels of phonological representation could potentially be admitted. It remains a task for further research in this area to determine whether such a model is empirically substantiated and whether membership in phonological categories should be conceptualised as scalar; cases like Scottish /ae/ discussed by Ladd (2006) suggest that this may indeed be the case.

\section{Conclusion}

In this paper, we have highlighted the need for empirical study of cases whose classification as either phonological or phonetic is contentious. Dutch $/ r /$ allophony is one such case, as it shows categorical phonetic properties which do not cue a lexical contrast. A closer investigation of the Dutch / $r$ / data reveals that the categorical properties of the allophonic variation are tied to complex patterns of reduction and coarticulation. Based on our findings, we have argued that no single criterion can be reliably used to determine what is and what is not phonological. Instead, we propose that phonological categories emerge from an array of conditioning factors, whose mutual relationship is potentially reflected in terms of representational hierarchies.

\section{Notes}

1. Using the F3 drop was the most consistent criterion we could find for selecting the relevant time points for analysis. As a consequence of this approach, we analysed only one frame per each token. In Section 3.4, we return to the issue of how this might have affected our results.

2. In our results, we do not discuss the results from intervocalic word-medial onsets $/ \mathrm{VrV} /$ or the word-final prevocalic context $/ \mathrm{Vr} \# \mathrm{~V} /$ in detail. These were found to pattern consistently with the onset and coda contexts respectively. This is an interesting finding in the context of word-final resyllabification and initial strengthening, but for the sake of brevity, we focus on the comparison between the fake geminate onset $/ \mathrm{r} \# \mathrm{r} /$ vs. canonical onset $/ \mathrm{V \# rV/}$ and canonical coda $/ \mathrm{Vr} \# \mathrm{C} /$.

3. A reviewer points out that the lack of neutralisation we observe between fake geminate and canonical onset need not necessarily entail that phonology computes non-contrastive features, because the contrast may reflect a prosodic rather than subphonemic distinction. Specifically, the fake geminate $/ \mathrm{r} / \mathrm{can}$ be represented as ambisyllabic, in which case it may combine phonetic features of onset and coda / $\mathrm{r} /$ variants. However, if this proposal were to comply with the assumptions of the contrastivist position (phonology only sees contrastive features), the articulatory properties of different $/ \mathrm{r}$ / variants would have to be translated directly from the prosodic representation to the phonetics. It is not clear to us how this view connects to current theories 
of the phonetics-phonology interface and phonetic implementation. What strikes us as particularly problematic is the implication that articulatory gestures can be categorically inserted or deleted in the absence of a feature.

4. Ladd uses the term 'phoneme' here to denote what we would call a 'phonological category'. In our discussion, we limit the use of the term 'phoneme' to those categories which are lexically contrastive.

\section{References}

Articulate Instruments Ltd. 2008. ultrasound stabilisation headset users manual: Revision 1.1. Edinburgh, UK: Articulate Instruments Ltd.

Articulate Instruments Ltd. 2010. Articulate assistant advanced ultrasound module user manual, revision 2.14. Edinburgh, UK: Articulate Instruments Ltd.

Avery, Peter, B. Elan Dresher \& Keren D. Rice (eds.). 2008. Contrast in phonology: Theory, perception, acquisition. Berlin: Mouton de Gruyter. DOI: 10.1515/9783110208603

Baayen, R. Harald. 2011. languageR: Data sets and functions with "Analyzing Linguistic Data: A practical introduction to statistics". < http://cran.r-project.org/web/packages/languageR/ index.html> (15 January 2014)

Boersma, Paul \& David Weenink. 2009. Praat: doing phonetics by computer [Computer program]. Version 5.1.12. <http://www.praat.org/ > (15 October 2009).

Browman, Catherine P. \& Louis Goldstein. 1992. Articulatory phonology: An overview. Phonetica 49. 155-180. DOI: 10.1159/000261913

Hall, Daniel Currie. 2007. The role and representation of contrast in phonological theory. $\mathrm{PhD}$ diss., University of Toronto.

Delattre, Pierre \& Donald C. Freeman. 1968. A dialect study of American $r$ s by x-ray motion picture. Linguistics 6. 29-68. DOI: 10.1515/ling.1968.6.44.29

Dresher, B. Elan. 2009. The contrastive hierarchy in phonology. Cambridge: Cambridge University Press. DOI: 10.1017/CBO9780511642005

Herd, Wendy, Allard Jongman \& Joan Sereno. 2010. An acoustic and perceptual analysis of /t/ and /d/ flaps in American English. Journal of Phonetics 38. 504-516.

DOI: $10.1016 /$ j.wocn.2010.06.003

Kahn, Daniel. 1980. Syllable-based generalizations in English phonology. New York: Garland.

Keyser, Samuel J. \& Kenneth N. Stevens. 2006. Enhancement and overlap in the speech chain. Language 82. 33-63. DOI: 10.1353/lan.2006.0051

Kingston, John \& Avis H. Cohen. 1992. Extending articulatory phonology. Phonetica 49. 194204. DOI: 10.1159/000261915

Ladd, D. Robert. 2006. 'Distinctive phones' in surface representation. In Louis M. Goldstein, Douglas. H. Whalen \& Catherine T. Best (eds.), Laboratory Phonology 8, 3-26. Berlin: Mouton de Gruyter.

Lodge, Ken. 2003. A declarative treatment of the phonetics and phonology of German rhymal /r/. Lingua 113. 931-951. DOI: 10.1016/S0024-3841(02)00142-0

Nespor, Marina \& Irene Vogel. 1986. Prosodic phonology. Dordrecht: Foris Publications.

Ohala, John J. 1990. There is no interface between phonology and phonetics: A personal view. Journal of Phonetics 18. 153-171. 
Pierrehumbert, Janet, Mary Beckman \& D. Robert Ladd. 2000. Conceptual foundations of phonology as a laboratory science. In Noel Burton-Roberts, Philip Carr \& Gerard Docherty (eds.), Phonological Knowledge, 273-303. Oxford: Oxford University Press.

Plug, Leendert \& Richard Ogden. 2003. A parametric approach to the phonetics of postvocalic /r/ in Dutch. Phonetica 60. 159-186. DOI: 10.1159/000073501

R Development Core Team. 2005. R: A language and environment for statistical computing. R Foundation for Statistical Computing, Vienna, Austria. ISBN 3-900051-07-0. <http:// www.R-project.org> (30 October 2013)

Ramsammy, Michael. 2013. Word-final nasal velarisation in Spanish. Journal of Linguistics 49. 215-255. DOI: 10.1017/S0022226712000187

Scobbie, James M. 2007. Interface and overlap in phonetics and phonology. In Gillian Ramchand \& Charles Reiss (eds.), Oxford Handbook of Linguistic Interfaces, 17-52. Oxford: Oxford University Press.

Scobbie, James M. \& Koen Sebregts. 2010. Acoustic, articulatory, and phonological perspectives on allophonic variation of /r/ in Dutch. In Rafaella Folli \& Christiane Ulbrich (eds.), Interfaces in Linguistics. New Research Perspectives, 257-277. Oxford: Oxford University Press.

Sebregts, Koen, Evie Tops, Renée van Bezooijen, Hans van de Velde, Roeland van Hout, Roland Willemyns \& Wim Zonneveld. 2003. Socio-grafische en linguïstische variatie in de uitspraak van de 'r'. Een onderzoek in Nederlandse en Vlaamse grote steden. In Tom Koole, Jacomine Nortier \& Bert Tahitu (eds.), Artikelen van de Vierde Sociolinguistische Conferentie, 375-385. Delft: Eburon.

Stevens, Kenneth N. \& Samuel J. Keyser. 1989. Primary features and their enhancement in consonants. Language 65. 81-106. DOI: 10.2307/414843

Stevens, Kenneth N. \& Samuel J. Keyser. 2010. Quantal theory, enhancement and overlap. Journal of Phonetics 38. 10-19. DOI: 10.1016/j.wocn.2008.10.004

Stevens, Kenneth N., Samuel J. Keyser \& Haruko Kawasaki. 1986. Toward a phonetic and phonological theory of redundant features. In Joseph S. Perkell \& Dennis H. Klatt (eds.), Invariance and Variability in Speech Processes, 426-449. Hillsdale: Lawrence Erlbaum.

Strycharczuk, Patrycja, Marijn van 't Veer, Martine Bruil \& Kathrin Linke. 2013. Phonetic evidence on phonology-morphosyntax interactions. Sibilant voicing in Quito Spanish. Journal of Linguistics. Available on CJO 2013 DOI: 10.1017/S0022226713000157.

Turton, Danielle. 2013. An ultrasound investigation of /l/-darkening in varieties of English. Paper presented at the 23rd Manchester Phonology Meeting, University of Manchester.

Van de Velde, H. 1996. Variatie en verandering in het Gesproken Standaard-Nederlands (19351993). Nijmegen: KUN.

Westbury, John R., Michiko Hashi \& Mary J. Lindstrom. 1998. Differences among speakers in lingual articulation for American English /x/. Speech Communication 26. 203-226. DOI: 10.1016/S0167-6393(98)00058-2

Yuan, Jiahong \& Mark Liberman. 2009. Investigating /1/ variation in English through forced alignment. Tenth Annual Conference of the International Speech Communication Association, 2215-2218. 


\section{Appendix. Stimuli used in the experiment}

\section{Test items}

\begin{tabular}{ll}
\hline $\begin{array}{l}\text { Heb je een paar eisen aan de accomodatie } \\
\text { gesteld? }\end{array}$ & $\begin{array}{l}\text { 'Did you make a few demands about the } \\
\text { accommodation?' } \\
\text { Heb je een paar reizen naar Manchester }\end{array}$ \\
$\begin{array}{l}\text { gemaakt? } \\
\text { Heeft je pa reizen naar Manchester gemaakt? }\end{array}$ & 'Has your dad made trips to Manchester?' \\
Heb je een Parijzenaar in Manchester ontmoet? & 'Did you meet a Parisian in Manchester?' \\
Heb je een paar meisjes in Manchester ontmoet? & 'Did you meet a few girls in Manchester?' \\
& 'Could that couple breathe in the thin air?' \\
Kon dat paar ademen in die ijle lucht? & 'Could that couple guess what was in the box?' \\
Kon dat paar raden wat er in de doos zat? & 'Could your dad guess what was in the box?' \\
Kon die parade niet doorgaan in de regen? & 'Could the parade not go ahead in the rain?' \\
Kon dat paar baden in de open lucht? & 'Could that couple bathe in the open air?' \\
\hline
\end{tabular}

\section{Distracters}

Heb je een stel laarzen bij die winkel gekocht? Heb je een hoop borden bij de afwas gezet?

Heeft je broer vakantie in Amerika gevierd?

Heb je een Amsterdammer in Zwolle ontmoet?

Heb je een stel jongens in Zwolle ontmoet?

Kon dat gezin praten met al dat lawaai?

Kon dat gezin zien wat er onder de Kerstboom lag?

Kon je zus weten wat er onder de Kerstboom lag?

Kon dat feest niet doorgaan zonder de gasten?

Kon dat stel eten in de achtertuin?

Kon je zus lopen op die schoenen?

Heb je een Amerikaan in China ontmoet?

Heeft je broer steeds in hotels overnacht?

Heb je de gordijnen zelf gemaakt?
'Did you buy a pair of boots in that shop?'

'Did you put a stack of plates with the dishes?'

'Did your brother take a holiday in America?'

'Did you meet a man from Amsterdam in Zwolle?'

'Did you meet a couple of boys in Zwolle?' 'Could that family talk with all that noise?' 'Could that family see what was under the Christmas tree?'

'Could your sister know what was under the Christmas tree?'

'Could that party not go ahead without the guests?'

'Could that couple eat in the back garden?' 'Could your sister walk in those shoes?' 'Did you meet an American in China?' 'Did your brother stay in hotels the whole time?'

'Did you make the curtains yourself?' 


\section{Authors' addresses}

Patrycja Strycharczuk

Clinical Audiology, Speech and Language Research Centre

Queen Margaret University

Queen Margaret University Drive

EH21 6UU Edinburgh, United Kingdom

pstrycharczuk@qmu.ac.uk
Koen Sebregts

Department of Languages, Literature and Communication

Utrecht University

Trans 10

3512 JK Utrecht, The Netherlands

k.sebregts@uu.nl 